\title{
Higher HEI-2015 Score Is Associated with Reduced Risk of Depression: Result from NHANES 2005-2016
}

\author{
Kai Wang ${ }^{1}{ }^{\oplus}$, Yudi Zhao ${ }^{2}{ }^{\oplus}$, Jiaqi Nie ${ }^{1}$, Haoling $\mathrm{Xu}^{1}{ }^{1}$, Chuanhua $\mathrm{Yu}^{2}{ }^{\circledR}$ and Suqing Wang ${ }^{1, *}$ \\ 1 Department of Nutrition and Food Hygiene, School of Health Science, Wuhan University, 185, Donghu Rd, \\ Wuhan 430071, China; wk1148761305@whu.edu.cn (K.W.); 15502730223@163.com (J.N.); \\ xuhlntl@163.com (H.X.) \\ 2 Department of Epidemiology and Biostatistics, School of Health Sciences, Wuhan University, 185 Donghu Rd, \\ Wuhan 430071, China; yudi_zhao@whu.edu.cn (Y.Z.); yuchua@whu.edu.cn (C.Y.) \\ * Correspondence: swang2099@whu.edu.cn
}

\section{check for}

updates

Citation: Wang, K.; Zhao, Y.; Nie, J.; Xu, H.; Yu, C.; Wang, S. Higher HEI-2015 Score Is Associated with Reduced Risk of Depression: Result from NHANES 2005-2016. Nutrients 2021, 13, 348. https://doi.org/ $10.3390 /$ nu13020348

Received: 17 December 2020

Accepted: 19 January 2021

Published: 25 January 2021

Publisher's Note: MDPI stays neutral with regard to jurisdictional claims in published maps and institutional affiliations.

Copyright: (c) 2021 by the authors. Licensee MDPI, Basel, Switzerland. This article is an open access article distributed under the terms and conditions of the Creative Commons Attribution (CC BY) license (https:// creativecommons.org/licenses/by/ $4.0 /)$.

\begin{abstract}
Globally, the total estimated number of people living with depression increased by $18.4 \%$ between 2005 and 2015, with the prevalence being 4.8\% in 2015. Many nutrient and diet patterns are proven to be correlated to depression, so we conducted this analysis to explore whether the Healthy Eating Index 2015 (HEI-2015) score is associated with depression, and possibly to provide dietary measures to reduce the risk of depression. Data came from the National Health and Nutrition Examination Survey (2005-2016), a cross-sectional and nationally representative database. The analytic sample was limited to adults: (1) age $\geq 20$ with complete information of HEI-2015 and depression; (2) no missing data of demographics, BMI, drinking, smoking, and fasting plasma glucose. HEI-2015 was calculated using the Dietary Interview: Total Nutrient Intakes, First Day data file. Depression was assessed using the Patient Health Questionnaire-9 (PHQ-9). Weighted logistic regression models were used to explore the relationship between the HEI-2015 score and depression. The final study sample included 10,349 adults, with $51.4 \%$ of them being men, representing a population of about 167.8 million non-institutionalized U.S. adults. After multivariable adjustment, average HEI status (OR: 0.848, 95\% CI: 0.846-0.849) and optimal HEI status (OR: 0.455, 95\% CI: 0.453-0.456) were associated with reduced odds of depression. Poor diet quality is significantly associated with elevated depressive symptoms in U.S. adults. Aligning with the Dietary Guidelines for Americans reduces the risk of depression.
\end{abstract}

Keywords: healthy eating index; depression; NHANES; diet pattern; DGA

\section{Introduction}

Depression, clinically characterized by significant and persistent low mood symptoms, is a common and growing globally mental health issue linked with considerably diminished role-functioning and quality of life, medical comorbidity, and mortality [1]. In 2017, about 17.3 million adults aged 18 and over in the US had experienced at least one major depressive episode. The prevalence was about $7.1 \%$, and highest among adults reporting two or more races [2]. According to the Depression and Other Common Mental Disorders: Global Health Estimates published by WHO in 2017, the total number of people living with depression in the world is 322 million. Nearly half of them live in the South-East Asia Region and Western Pacific Region, such as China and India. Meanwhile, the prevalence of depression varies by age, peaking in older adulthood, and was estimated above $7.5 \%$ among females aged 55-74 years [3]. A substantial number of researches have shown strong relationships between depression and physical health, including cardiovascular disease [4], Parkinson's disease [5], metabolic disease [6], dementia [7], type 2 diabetes [8], and cancer [9]. Out of the mental and addictive disorders, depressive disorders cause most disability-adjusted life years for both sexes, followed by anxiety disorders in women [10]. In 2015, depressive disorders led to a global total of over 50 million years lived with disability (YLD), more than 
$80 \%$ of which occurred in low- and middle-income countries [4]. Studies in recent decades have shown associations between nutrient intake and the risk of depression, including minerals like zinc, omega-3 fatty acids, and vitamins such as vitamin D [11-14]. Many researchers also found adherence to a specific dietary pattern, such as "dietary approaches to stop hypertension", was correlated with lower depression risk [15-17]. While most of them focused on specific diet pattern or food intake, some research explored the relationship from a macroscopic view. To explore the effect of diet quality in a more macroscopic way, we adopted the latest edition of the Healthy Eating Index (HEI) to determine whether diet quality is related to depression. Through this research, we want to answer whether aligning with the Dietary Guidelines for Americans (DGA) reduces the risk of depression.

\section{Materials and Methods}

\subsection{Sample}

Data came from the six continuous National Health and Nutrition Examination Survey (NHANES) cycles from 2005-2016 (https:/ / wwwn.cdc.gov/nchs/nhanes/ContinuousNhanes/ Default.aspx?BeginYear=2005). NHANES is a nationally representative, population-based survey for assessing adult and child health and nutritional status in the US. This survey combined health interviews conducted in respondents' homes with health measurements (e.g., DPQ_I, objective physical measures) performed at mobile exam centers (MECs). The examination components consisted of medical, dental, and physiological measurements, and laboratory tests supervised by trained medical personnel. Furthermore, the adoption of various modern equipment enabled the NHANES to collect reliable, high-quality data. Moreover, compensation and a report of medical findings were given to each participant, which increased the compliance of participants [18]. The total sample size of adults from the 2005-2016 assessments was $\mathrm{N}=10,349$. Additional details of the study design, sampling, and exclusion criteria are described in Figure 1. Only publicly available data was used in the analysis, and no ethical approval was needed in this study.

\subsection{Measures}

Diet quality: The Healthy Eating Index (HEI) is a measure for assessing dietary quality, precisely, the degree to which a set of foods aligns with the Dietary Guidelines for Americans [19]. The HEI-2015 components were the same as in the HEI-2010, except saturated fat and added sugars replaced empty calories, with the result being 13 components [20]. HEI-2015 scores ranged from 0-100, with higher HEI scores reflecting better diet quality. We utilized the total nutrient intakes on the first day (DR1TOT) to calculate the 13 components of HEI-2015. For further weighted Scott-Rao chi-square test and weighted logistic regressions, an HEI-2015 score less than 50, between 50 and 70, and more than 70 was categorized as inadequate, average and optimal, respectively [21].

Depression: Current depressive symptoms were measured by the Patient Health Questionnaire-9 (PHQ-9). The PHQ-9 is a well-validated (Cronbach's $\alpha=0.89$ ) self-report instrument that assesses depression symptoms (i.e., sadness, trouble sleeping, fatigue, problems concentrating) in the past two weeks, and has moderate concordance with clinical psychiatric interviews. The PHQ-9 questionnaire contains nine items, with each item being assessed on a four-point Likert scale, ranging from $0=$ not at all to $3=$ nearly every day, and summing up a total scale range of 0 to 27. A dichotomous variable indicating no depression (PHQ-9 score $<10$ ) or elevated depressive symptoms (PHQ-9 score $\geq 10$ ) was created using a threshold score of 10 [22]. 


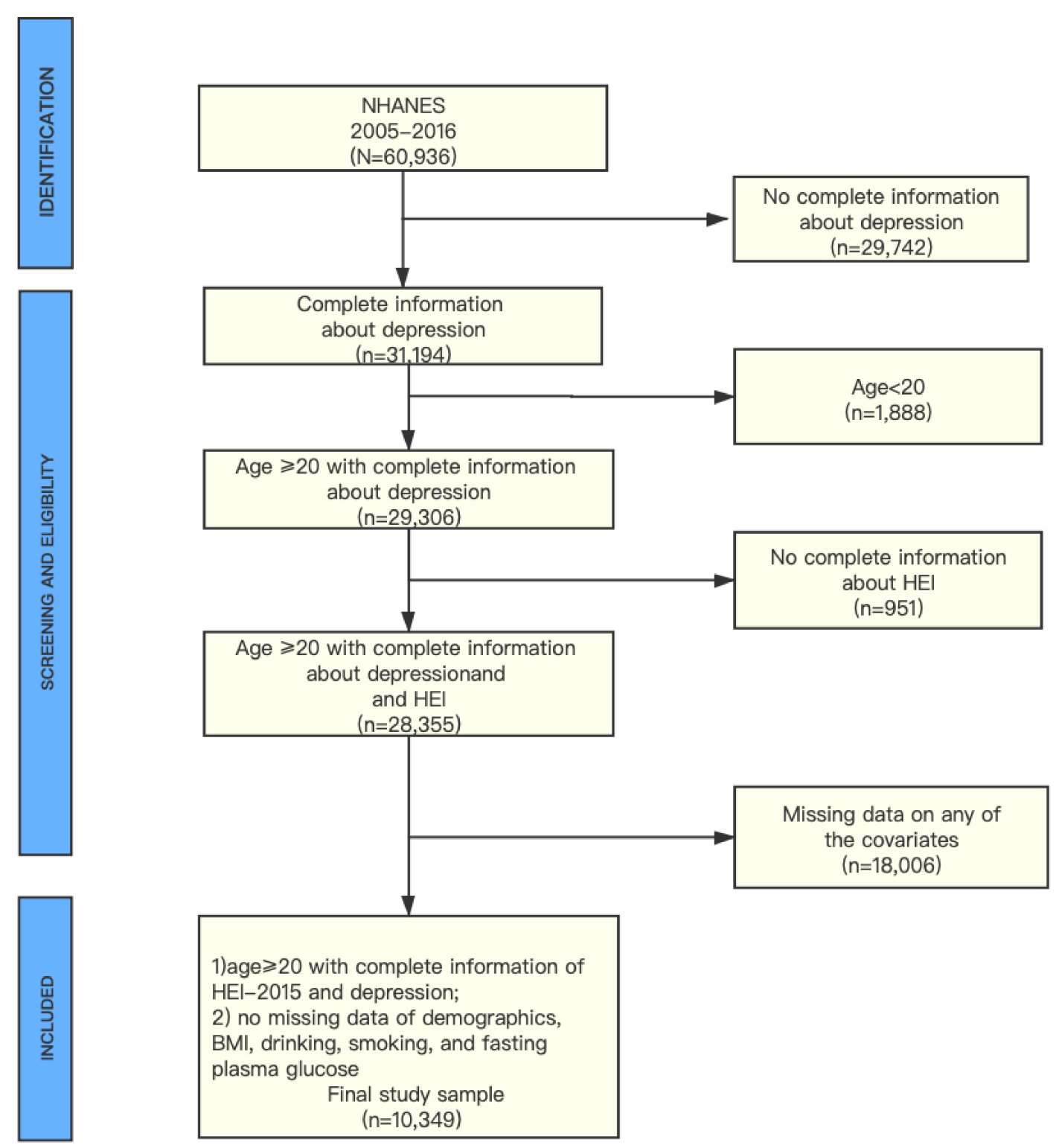

Figure 1. Flowchart of the study population.

\section{Covariates}

Each covariant was categorized into a reference group, and other groups. When analyzing, all other groups were compared to this reference group to estimate the relative odds ratio.

Sex: Sex was categorized as male (reference group) and female.

Age: Age was categorized as 20 to 25 years (reference group), 26 to 49 years, and $50+$ years [4].

Race: Race was categorized as non-Hispanic white (reference group), non-Hispanic black, Mexican American, and other races [23].

Education level: Education level was categorized as less than a high school diploma (reference group), high school graduate/GED, some college/AA degree, and college graduate or more [24].

Household income: Household income was categorized as $\leq 130 \%$ (reference group), $>130 \%$ to $350 \%$, and $>350 \%$ by the ratio of family income to poverty (FPL) [25]. 
BMI status: body mass index was calculated from measured height and weight as weight/height ${ }^{2}\left(\mathrm{~kg} / \mathrm{m}^{2}\right)$, and then categorized into $\leq 25$ (reference group), $>25$ to 30 , and $>30$ [26].

Smoking status: smoking behavior was measured in the "smoking: cigarette use" questionnaire. In the "smoking: cigarette use" questionnaire, respondents were asked if $\mathrm{s} /$ he had smoked at least 100 cigarettes in their life, and smoked cigarettes when being questioned. If the respondent had smoked less than 100 cigarettes in their life, s/he was classified as a never smoker. If the respondent had smoked at least 100 cigarettes in his/her life and still smoked when $\mathrm{s} /$ he answered the questionnaire, $\mathrm{s} /$ he was classified as a current smoker. The respondent was classified as a former smoker if $\mathrm{s} /$ he had smoked at least 100 cigarettes in his/her life, and had quit smoking when s/he answered the questionnaire. Smoking status was categorized into never smoker (reference group), former smoker, and current smoker [27].

Drinking status: drinking behavior was measured in the "alcohol use" questionnaire. In the "alcohol use" questionnaire, each respondent was asked how often s/he had drunk alcoholic drinks in the past 12 months, and the average drinks on those days that s/he drank alcoholic beverages. According to these questions, the average number of alcoholic drinks consumed per week in the past 12 months could be calculated. Then it was categorized into four strata $(0,<1,1-<8$, and $\geq 8$ drinks per week) and defined as none (reference group), light, moderate, and heavy alcohol consumption, respectively. A "drink" was defined as a 12-ounce beer, a 5-ounce glass of wine, or one-and-half ounces of liquor [28].

Diabetes: plasma glucose data were obtained from the plasma fasting glucose laboratory data. Respondents whose fasting plasma glucose was $\geq 6.0 \mathrm{mmol} / \mathrm{L}$ were thought to be a diabetic, consistent with American Diabetes Association guidelines [29]. Thus, respondents were categorized into adults with normoglycemia (reference group), and adults with diabetes.

\subsection{Statistical Analysis}

Initially, the trends of depression and other characteristics in the six continuous cycles were estimated with the Cochran-Armitage trend test. Then, the baseline characteristics of different groups were compared using the weighted Scott-Rao chi-square test [30]. HEI scores were described with a median (P25, P75). Finally, a series of weighted steps forward (likelihood ratio) binary logistic regression models were fit to assess the relationship between diet quality and depression. Estimates were weighted to be representative of the general adult population. All $p$ values refer to two-tailed tests. Statistical analyses were conducted using the SPSS statistical package (Version 23.0; SPSS Inc., Chicago, IL, USA).

\section{Results}

Figure 1 described the study design, sampling, and exclusion; and 18,006 participants were excluded because of missing data on any of the covariates. Among them, $2361,12,219,12,3594$, and 11,808 individuals were excluded because of missing data on income, education, BMI, smoking, drinking, and diabetes, respectively. Our final sample included 10,349 NHANES participants, representing a population of about 167.8 million non-institutionalized U.S. adults, with $48.6 \%$ being female and $72.0 \%$ being nonHispanic White.

Table 1 described the prevalence of depression and associated characteristics in six continuous NHANES cycles, in which the trend tests were also conducted. The prevalence of depression grew with time, from $4.8 \%$ in $2005-2006$ to $7.4 \%$ in 2015-2016. In addition, there are other points worth noting. For example, the proportion of women and adults aged over fifty years old increased with time. The proportion of adults with normal or low weight decreased with time, indicating the urgency of body shape management. The prevalence of diabetes increased with time, which reminds adults of the significance of blood glucose control. The proportion of adults with inadequate HEI status decreased with time, showing the improving diet quality in the six cycles. 
Table 1. US trends in characteristics among adults aged 20 years or older.

\begin{tabular}{|c|c|c|c|c|c|c|c|}
\hline Characteristics & $\begin{array}{l}2005-2006 \\
(n=1595)\end{array}$ & $\begin{array}{c}2007-2008 \\
(n=1839)\end{array}$ & $\begin{array}{r}2009-2010 \\
(n=1913)\end{array}$ & $\begin{array}{c}2011-2012 \\
(\mathrm{n}=1619)\end{array}$ & $\begin{array}{l}2013-2014 \\
(n=1778)\end{array}$ & $\begin{array}{l}2015-2016 \\
(n=1605)\end{array}$ & $p$ Trend \\
\hline $\begin{array}{l}\text { No. with depressive } \\
\text { symptoms }\end{array}$ & 84 & 157 & 166 & 131 & 159 & 139 & \\
\hline $\begin{array}{l}\text { The prevalence of } \\
\text { depression (Weighted \%) }\end{array}$ & 4.8 & 6.8 & 7.0 & 7.4 & 8.0 & 7.4 & $<0.001$ \\
\hline Sex (No. Weighted \%) & & & & & & & $<0.001$ \\
\hline Male & $856(51.2)$ & $993(52.7)$ & $983(51.4)$ & $891(52.0)$ & $710(50.7)$ & $856(50.6)$ & \\
\hline Female & $739(48.8)$ & $846(47.3)$ & $930(48.7)$ & $728(48.0)$ & $868(49.3)$ & $749(49.4)$ & \\
\hline $\begin{array}{c}\text { Age group (No. Weighted } \\
\%)\end{array}$ & & & & & & & $<0.001$ \\
\hline $20-24 y$ & $151(8.9)$ & $136(9.1)$ & $175(9.3)$ & $171(9.6)$ & $143(9.5)$ & $115(7.2)$ & \\
\hline $25-49 y$ & $746(51.5)$ & $775(51.0)$ & $809(47.6)$ & $709(46.3)$ & $764(45.4)$ & $670(44.8)$ & \\
\hline $50+y$ & $698(39.6)$ & $928(39.9)$ & $929(43.1)$ & $739(44.1)$ & $871(45.0)$ & $820(45.8)$ & \\
\hline Race (No. Weighted \%) & & & & & & & $<0.001$ \\
\hline Non-Hispanic White & $865(75.2)$ & $932(72.6)$ & $1023(73.9)$ & $728(71.9)$ & $868(70.2)$ & $646(68.7)$ & \\
\hline Non-Hispanic Black & $334(9.7)$ & $364(10.4)$ & $298(9.8)$ & $366(10.1)$ & 339 (10.7) & $321(10.1)$ & \\
\hline Mexican American & $281(7.2)$ & $304(8.0)$ & $331(7.3)$ & $159(6.6)$ & $224(8.3)$ & $240(7.1)$ & \\
\hline Other races & $115(7.9)$ & $239(9.0)$ & $261(9.0)$ & $366(11.4)$ & $347(10.8)$ & $398(14.1)$ & \\
\hline $\begin{array}{c}\text { Education level (No. } \\
\text { Weighted \%) }\end{array}$ & & & & & & & $<0.001$ \\
\hline$<$ High school & $373(14.8)$ & 509 (17.5) & 475 (16.2) & $323(14.0)$ & $345(14.2)$ & $306(11.9)$ & \\
\hline High school/GED & $400(26.2)$ & $453(23.8)$ & $434(22.7)$ & $340(18.7)$ & $384(20.1)$ & $374(22.3)$ & \\
\hline Some college/AA degree & $483(32.8)$ & $478(29.4)$ & $567(30.6)$ & $500(33.1)$ & $557(33.2)$ & $506(32.6)$ & \\
\hline College or more & $339(26.1)$ & $399(29.4)$ & $437(31.4)$ & $456(34.2)$ & $492(32.5)$ & $419(33.1)$ & \\
\hline $\begin{array}{c}\text { Household income (No. } \\
\text { Weighted \%) }\end{array}$ & & & & & & & $<0.001$ \\
\hline $0-130 \%$ FPL & $352(13.3)$ & $503(17.3)$ & $598(20.5)$ & $540(21.8)$ & $574(23.1)$ & $463(18.2)$ & \\
\hline$>130-350 \%$ FPL & $652(39.1)$ & $718(33.6)$ & $711(36.0)$ & $576(36.6)$ & $610(34.3)$ & $665(37.9)$ & \\
\hline$>350 \% \mathrm{FPL}$ & $591(47.6)$ & $618(49.1)$ & $604(43.4)$ & $503(41.9)$ & $594(42.6)$ & $477(43.3)$ & \\
\hline $\begin{array}{c}\text { BMI status (No. Weighted } \\
\%)\end{array}$ & & & & & & & $<0.001$ \\
\hline Normal or low weight & $479(32.0)$ & $538(31.6)$ & $540(31.0)$ & $503(31.2)$ & $535(30.0)$ & $422(26.1)$ & \\
\hline Overweight & $537(31.9)$ & $653(36.1)$ & $665(34.0)$ & $528(33.6)$ & $589(33.2)$ & $534(32.5)$ & \\
\hline Obese & $579(36.2)$ & $648(32.3)$ & $708(34.9)$ & $588(35.2)$ & $654(36.9)$ & $649(41.4)$ & \\
\hline $\begin{array}{l}\text { Smoking status (No. } \\
\text { Weighted \%) }\end{array}$ & & & & & & & $<0.001$ \\
\hline Never & $721(44.6)$ & $863(50.1)$ & $950(51.4)$ & $853(54.1)$ & $911(53.2)$ & $767(48.1)$ & \\
\hline Former & $482(28.5)$ & $528(26.7)$ & $531(28.0)$ & $413(25.5)$ & $481(26.8)$ & $469(31.1)$ & \\
\hline Current & $392(27.2)$ & $448(23.1)$ & $432(20.6)$ & $353(20.5)$ & $386(20.0)$ & $369(20.8)$ & \\
\hline $\begin{array}{l}\text { Drinking status (No, } \\
\text { Weighted \%) }\end{array}$ & & & & & & & $<0.001$ \\
\hline None & $394(19.0)$ & $434(18.5)$ & $385(16.1)$ & 315 (15.3) & $362(15.6)$ & 307 (15.7) & \\
\hline Light & $516(33.4)$ & $620(33.9)$ & $682(34.0)$ & $591(34.9)$ & $656(36.5)$ & $606(36.0)$ & \\
\hline Moderate & $457(30.7)$ & $514(32.1)$ & $546(33.3)$ & $453(31.2)$ & $522(33.3)$ & $483(34.3)$ & \\
\hline Heavy & $228(16.8)$ & $271(15.5)$ & $300(16.7)$ & $238(18.6)$ & $238(14.6)$ & $209(13.9)$ & \\
\hline Diabetes (No. Weighted \%) & & & & & & & $<0.001$ \\
\hline No & $1448(93.0)$ & 1617 (92.6) & $1707(92.3)$ & $1445(92.5)$ & $1570(90.2)$ & $1370(88.7)$ & \\
\hline Yes & $147(7.0)$ & $222(7.4)$ & $206(7.7)$ & $174(7.5)$ & $208(9.8)$ & $235(11.3)$ & \\
\hline $\begin{array}{c}\text { HEI status (No. Weighted } \\
\% \text { ) }\end{array}$ & & & & & & & $<0.001$ \\
\hline Inadequate & $889(57.2)$ & $959(55.2)$ & $958(49.3)$ & 825 (49.7) & 895 (50.9) & $758(47.3)$ & \\
\hline Average & $594(36.4)$ & $751(38.6)$ & $789(41.3)$ & $652(39.8)$ & $704(40.1)$ & $720(45.1)$ & \\
\hline Optimal & $112(6.4)$ & $129(6.1)$ & $166(9.4)$ & $142(10.5)$ & $179(9.1)$ & $127(7.5)$ & \\
\hline
\end{tabular}

Values are survey-weighted percentages. FPL = family income to poverty. HEI = healthy eating index.

Table 2 describes the characteristics of participants with the weighted Scott-Rao chisquare test. Adults with depression were more likely to be female, non-Hispanic Black, 
obese, over 50 years old, current smokers, diabetic, alcoholic, have less than high school education, have low household income, and have inadequate HEI scores.

Table 2. Characteristics among adults aged 20 years or older by depression.

\begin{tabular}{|c|c|c|c|}
\hline Characteristics & Adults without Depression & Adults with Depression & $p$-Value \\
\hline No. (Weighted \%) & 9513 (93.1) & $836(6.9)$ & \\
\hline Sex & & & $<0.001$ \\
\hline Male & $5159(52.4)$ & $330(38.1)$ & \\
\hline Female & $4354(47.6)$ & $506(61.9)$ & \\
\hline Age group & & & $<0.001$ \\
\hline $20-24$ y & $4129(9.5)$ & $326(7.4)$ & \\
\hline $25-49 y$ & $3212(47.9)$ & $368(45.6)$ & \\
\hline $50+y$ & $2172(42.6)$ & $142(47.1)$ & \\
\hline Race & & & $<0.001$ \\
\hline Non-Hispanic White & $4654(72.3)$ & $408(69.1)$ & \\
\hline Non-Hispanic Black & $1846(9.9)$ & $176(13.5)$ & \\
\hline Mexican American & $1430(7.5)$ & $109(6.2)$ & \\
\hline Other races & $1583(10.3)$ & $143(11.2)$ & \\
\hline Education level & & & $<0.001$ \\
\hline$<$ High school & $2052(14.0)$ & $279(24.9)$ & \\
\hline High school/GED & $2176(21.8)$ & $209(26.3)$ & \\
\hline Some college/AA degree & $2841(31.8)$ & $250(34.4)$ & \\
\hline College or more & $2444(32.4)$ & $98(14.5)$ & \\
\hline Household income & & & $<0.001$ \\
\hline $0-130 \%$ FPL & $2574(17.4)$ & $456(42.3)$ & \\
\hline$>130-350 \%$ FPL & $3667(36.2)$ & $265(35.7)$ & \\
\hline$>350 \%$ FPL & $3272(46.4)$ & $115(22.0)$ & \\
\hline BMI status & & & $<0.001$ \\
\hline Normal or low weight & $2795(30.4)$ & $222(28.7)$ & \\
\hline Overweight & $3293(34.2)$ & $213(24.8)$ & \\
\hline Obese & $3425(35.4)$ & $401(46.5)$ & \\
\hline Smoking status & & & $<0.001$ \\
\hline Never & 4787 (51.6) & $278(31.8)$ & \\
\hline Former & $2695(28.0)$ & $209(24.3)$ & \\
\hline Current & $2031(20.3)$ & $349(44.0)$ & \\
\hline Drinking status & & & $<0.001$ \\
\hline None & 1979 (16.2) & $218(23.0)$ & \\
\hline Light & 3336 (34.6) & $335(37.9)$ & \\
\hline Moderate & $2833(33.4)$ & $142(20.6)$ & \\
\hline Heavy & 1365 (15.8) & $141(18.5)$ & \\
\hline Diabetes & & & $<0.001$ \\
\hline No & $8463(92.0)$ & $694(85.6)$ & \\
\hline YES & $1050(8.0)$ & $142(14.4)$ & \\
\hline HEI status & & & $<0.001$ \\
\hline Inadequate & $4783(50.8)$ & $501(62.4)$ & \\
\hline Average & 3908 (40.7) & $302(34.3)$ & \\
\hline Optimal & $822(8.5)$ & $33(3.2)$ & \\
\hline
\end{tabular}

Values are survey-weighted percentages. FPL = family income to poverty.

Table 3 shows the results of three weighted logistic regression models. Model 1 was adjusted for demographics characteristics (i.e., sex, age group, race, income, and education). Model 2 was adjusted for all Model 1 covariates and BMI, smoking, and drinking status. Moreover, Model 3 was adjusted for all Model 2 covariates and diabetes. After adjusting for demographic characteristics, optimal HEI status was associated with 0.378 times lower odds (95\% CI, 0.377-0.379) of current depression, relative to inadequate HEI status. Additional adjustment for BMI, smoking, drinking, and diabetes status did not substantially attenuate these relationships. After multivariable adjustment, adults with average HEI status (OR: 0.848, 95\% CI: $0.846-0.849$ ) and optimal HEI status (OR: 0.455, 95\% CI: 0.453-0.456) were associated with 
reduced odds of depression. Adults with diabetes were more likely to suffer from depression, with the odds ratio being 1.637 (95\% CI: 1.634-1.640).

Table 3. Relationship between HEI and Depression among Adults aged 20 years or older.

\begin{tabular}{|c|c|c|c|}
\hline \multirow{2}{*}{ Variable } & \multicolumn{3}{|c|}{ OR $(95 \%$ CI $)$} \\
\hline & Model 1 & Model 2 & Model 3 \\
\hline \multicolumn{4}{|l|}{ Sex (reference, Male) } \\
\hline Female & $1.799(1.787,1.791)$ & $1.850(1.847,1.852)$ & $1.889(1.887,1.892)$ \\
\hline \multicolumn{4}{|l|}{ Age group (reference, 20-24 y) } \\
\hline $25-49 y$ & $1.669(1.665,1.673)$ & $1.495(1.491,1.499)$ & $1.472(1.468,1.476)$ \\
\hline $50+y$ & $2.128(2.123,2.133)$ & $1.968(1.963,1.973)$ & $1.827(1.822,1.832)$ \\
\hline \multicolumn{4}{|c|}{ Race (reference, Non-Hispanic White) } \\
\hline Non-Hispanic Black & $0.963(0.961,0.965)$ & $0.958(0.956,0.960)$ & $0.958(0.956,0.960)$ \\
\hline Mexican American & $0.535(0.534,0.537)$ & $0.670(0.668,0.672)$ & $0.656(0.655,0.658)$ \\
\hline Other races & $0.976(0.974,0.978)$ & $1.062(1.060,1.064)$ & $1.048(1.046,1.050)$ \\
\hline \multicolumn{4}{|c|}{ Education level (reference, <High school) } \\
\hline High school/GED & $0.812(0.810,0.813)$ & $0.848(0.846,0.849)$ & $0.852(0.850,0.853)$ \\
\hline Some college/AA degree & $0.835(0.833,0.836)$ & $0.952(0.950,0.953)$ & $0.962(0.961,0.964)$ \\
\hline College or more & $0.479(0.478,0.480)$ & $0.647(0.646,0.649)$ & $0.655(0.653,0.656)$ \\
\hline \multicolumn{4}{|c|}{ 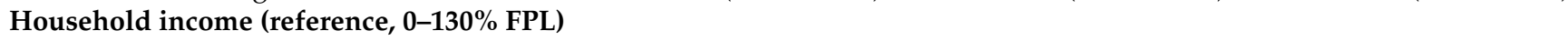 } \\
\hline$>130-350 \%$ FPL & $0.407(0.406,0.407)$ & $0.456(0.456,0.457)$ & $0.456(0.455,0.457)$ \\
\hline$>350 \%$ FPL & $0.230(0.230,0.231)$ & $0.274(0.273,0.274)$ & $0.277(0.276,0.277)$ \\
\hline \multicolumn{4}{|c|}{ HEI status (reference, Inadequate) } \\
\hline Average & $0.766(0.765,0.767)$ & $0.842(0.841,0.843)$ & $0.848(0.846,0.849)$ \\
\hline Optimal & $0.378(0.377,0.379)$ & $0.448(0.447,0.450)$ & $0.455(0.453,0.456)$ \\
\hline \multicolumn{4}{|c|}{ BMI (reference, Normal or low weight) } \\
\hline Overweight & & $0.844(0.843,0.846)$ & $0.833(0.832,0.835)$ \\
\hline Obese & & $1.341(1.339,1.343)$ & $1.265(1.263,1.267)$ \\
\hline \multicolumn{4}{|c|}{ Smoking status (reference, Never) } \\
\hline Former & & $1.286(1.284,1.288)$ & $1.274(1.272,1.276)$ \\
\hline Current & & $2.546(2.542,2.550)$ & $2.564(2.560,2.568)$ \\
\hline \multicolumn{4}{|c|}{ Drinking status (reference, None) } \\
\hline Light & & $0.955(0.954,0.957)$ & $0.971(0.969,0.973)$ \\
\hline Moderate & & $0.702(0.701,0.703)$ & $0.722(0.720,0.723)$ \\
\hline Heavy & & $1.141(1.139,1.144)$ & $1.181(1.179,1.184)$ \\
\hline \multicolumn{4}{|l|}{ Diabetes (reference, No) } \\
\hline YES & & & $1.637(1.634,1.640)$ \\
\hline
\end{tabular}

FPL = family income to poverty; CI = confidence interval; OR = odds ratio. Model 1 = adjusted for demographics characteristics (i.e., sex, age group, race, income, and education); Model 2 = Model 1 covariates + BMI, smoking, and drinking status; Model $3=$ Model 2 covariates + diabetes.

Figure 2 shows the trend of the HEI-2015 score in the form of a violin plot. HEI score increased from $47.77(39.39,56.51)$ in 2005-2006, to $50.74(43.13,59.13)$ in 2015-2016. The proportion of adults with inadequate HEI status decreased with time, and that of adults with optimal HEI status increased with time.

Figure 3 shows the results of three weighted logistic regression models in the form of a forest plot. As is shown, average and optimal HEI status are both protective factors for depression, reducing the depression risk by $15.2 \%$ and $54.5 \%$. Diabetes is the risk factor of depression, increasing the depression risk by $63.7 \%$. Cigarette smoking and heavy drinking are both behavioral risk factors. 


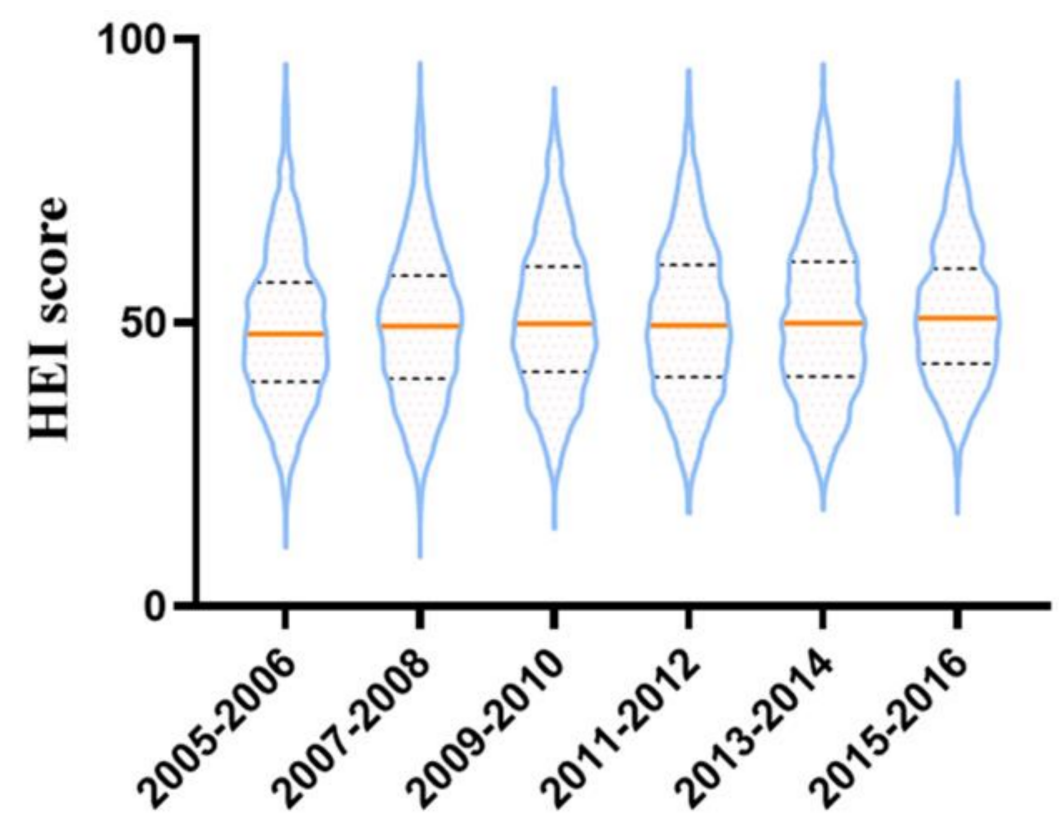

Figure 2. The trends of HEI-2015 score in the six cycles from 2005-2016 in NHANES.

Feature2
Male
Female
$20-24 \mathrm{y}$
$25-49 \mathrm{y}$
$50+\mathrm{y}$

Figure 3. The forest plot shows the odds ratios of analyzing variables in three weighted logistic regression models.

\section{Discussion}

The results revealed that a higher HEI score was significantly correlated to less elevated depression symptoms, so we concluded that higher diet quality was significantly correlated to a lower risk of depression. Our findings also suggest that Mexican Americans are less likely to suffer from depression, which needs further analyses of genetic factors.

We analyzed the depression status of participants from nine symptomatic questions from the PHQ in 2005-2016 NHANES data, and the results revealed a depression prevalence of $6.9 \%$. Since the sample is generalizable to the non-institutionalized civilian U.S. 
population, we assume the prevalence to be credible, similar to the data published by the WHO in 2017.

To our knowledge, many factors are associated with the occurrence of depression, for instance, alcohol consumption and diabetes. Moreover, it has been found by many researchers that women are more susceptible to depression than men [31-33], in accordance with our results (odds ratio, 1.889). Moreover, three logistic regression models were adopted in this analysis to explore a more appropriate model.

Some results have been widely recognized by many researchers. For example, the results of the weighted logistic models revealed that the risk of adults aged over 50 years old suffering from depression was 1.827 times that of adults aged 20-24 years old. The report from the $\mathrm{WHO}$ also concluded that the prevalence varies by age, peaking in older adulthood, similar to our results [3]. After multivariable adjustment, the odds ratio for other races changed from less than one, to more than one, which needs more specific classification. Our results revealed higher education level reduced the depression risk, similar to other studies [34-36]. In addition, our results revealed a negative correlation between household income and depression, consistent with other research [37-39]. It is recognized by many experts that a positive association exists between smoking and depression, as in our results [40-42]. Among the results, we found some interesting facts. Compared with normal and low weight participants, overweight adults were less likely to suffer from depression, contrary to our original thoughts. However, we found that Z Ul-Haq got a similar result from a cross-sectional study consisting of 37,272 participants, which revealed that overweight participants had better mental health than the normal-weight group [43]. Generally, overweight and obese adults suffer more ridicule and gossip than normal and low weight adults, which may be a reason for depression. After further analyses, we found that overweight adults accounted for about one third of American adults, so were obese adults. This meant high BMI is typical among American adults, and discrimination in the US is not as high as in China, leading to less psychological pressure in overweight adults. At the same time, overweight adults relieve pressure through diet, and are less susceptible to depression.

Another fact is that light and moderate drinking is a protective factor for depression. A meta-analysis in 2013 concluded that light drinking increased the risk of cancer of the oral cavity and pharynx, esophagus, and female breast [44]. However, many researchers have found that light and moderate drinking also have some health benefits, including reducing the risk of dementia [45], heart failure [46], ischemic stroke [47], type 2 diabetes [48], and allcause mortality [49]. In a cohort study with ten years of follow up, a J-shaped association was found with increased psychological distress among abstainers and heavy drinkers compared to light or moderate drinkers [50]. Our analysis believes that light and moderate drinking helps people deal with emotional issues and refresh themselves, thus reducing the risk of depression.

Physical activity has been found to be correlated to depression in a substantial number of studies [51-54]. However, three versions of the physical activity questionnaire were adopted in 2005-2016, and no identical and detailed information could be used to conduct an analysis. Therefore, physical activity was not included as a covariant in this analysis.

Diet quality was reported to be correlated to diabetes in many studies, not only in randomized controlled trials, but also in large population-based cohorts [55,56]. The relationship between diabetes and depression was recognized by R J Anderson in 2001 [57], yet whether there is a causal relationship is still under debate.

Thus, we conducted a mediation analysis to figure out whether diet quality influenced depression through diabetes. The HEI-2015 score was the independent variable, and the PHQ-9 score was the dependent variable. The result showed a mediating effect, but the mediating effect's proportion was only $0.14 \%$. For further mechanism analysis, we need to explore more possible factors causing the mediation effect.

The present study has several limitations. The cross-sectional design of the study is the primary limitation, and no causation should be inferred from this study. Second, using 
self-reported 24-h dietary recall data and the PHQ-9 questionnaire is a limitation, as they are subject to over- or under-reporting. Finally, 18,006 participants were excluded because of missing data on any of the covariates, which may have affected the results. Despite these limitations, our study has several strengths. Using a large, nationally representative database to estimate diet quality is a major strength of the present study. Adopting the latest edition of HEI is another strength. Moreover, data in six cycles were combined to increase the sample size.

Since we found that a higher HEI-2015 score is associated with a lower risk of depression, the next step of our plan is to figure out the pathway by which HEI-2015 influences depression, with structural equation models.

By virtue of this article, we would like to make the public aware of the significance of better diet quality on depression. Since better diet quality is associated with less depression risk, why do we not improve our diet quality to reduce the risk of depression?

\section{Conclusions}

This study's primary finding is that depression is rapidly growing in prevalence among American adults, from 4.8\% in 2005-2006, to 7.4\% in 2015-2016. Poor diet quality is significantly associated with elevated depressive symptoms. An optimal HEI-2015 score reduces the risk of suffering from elevated depressive symptoms by $54.5 \%$ compared to an inadequate HEI-2015 score.

Author Contributions: Conceptualization, K.W.; methodology, K.W. and C.Y.; software, K.W. and S.W.; validation, K.W. and S.W.; formal analysis, K.W.; investigation, K.W.; resources, S.W.; data curation, K.W.; writing — original draft preparation, K.W.; writing—review and editing, Y.Z.; visualization, K.W. and C.Y.; supervision, J.N.; project administration, H.X. All authors have read and agreed to the published version of the manuscript.

Funding: This research received no external funding.

Institutional Review Board Statement: Not applicable.

Informed Consent Statement: Not applicable.

Data Availability Statement: Publicly available datasets were analyzed in this study. This data can be found here: [https://wwwn.cdc.gov/nchs/nhanes/ContinuousNhanes/Default.aspx?BeginYear= 2005].

Conflicts of Interest: The authors declare no conflict of interest.

\section{References}

1. Park, L.T.; Zarate, C.A., Jr. Depression in the Primary Care Setting. N. Engl. J. Med. 2019, 380, 559-568. [CrossRef] [PubMed]

2. Anxiety and Depression Association of America. Available online: https://adaa.org/understanding-anxiety/depression\#Types\% 20of\%20Depression (accessed on 17 August 2020).

3. World Health Organization. Available online: https://www.who.int/publications/i/item/depression-global-health-estimates (accessed on 19 July 2020).

4. Carney, R.M.; Freedland, K.E. Depression and coronary heart disease. Nat. Rev. Cardiol. 2017, 14, 145-155. [CrossRef] [PubMed]

5. Wang, S.; Mao, S.; Xiang, D.; Fang, C. Association between depression and the subsequent risk of Parkinson's disease: A metaanalysis. Prog. Neuropsychopharmacol. Biol. Psychiatry 2018, 86, 186-192. [CrossRef]

6. Hidese, S.; Asano, S.; Saito, K.; Sasayama, D.; Kunugi, H. Association of depression with body mass index classification, metabolic disease, and lifestyle: A web-based survey involving 11,876 Japanese people. J. Psychiatr. Res. 2018, 102, 23-28. [CrossRef] [PubMed]

7. Byers, A.L.; Yaffe, K. Depression and risk of developing dementia. Nat. Rev. Neurol. 2011, 7, 323-331. [CrossRef]

8. Nouwen, A.; Winkley, K.; Twisk, J.; Lloyd, C.E.; Peyrot, M.; Ismail, K.; Pouwer, F.; European Depression in Diabetes (EDID) Research Consortium. Type 2 diabetes mellitus as a risk factor for the onset of depression: A systematic review and meta-analysis. Diabetologia 2010, 53, 2480-2486. [CrossRef]

9. Wakefield, C.E.; Butow, P.N.; Aaronson, N.A.; Hack, T.F.; Hulbert-Williams, N.J.; Jacobsen, P.B.; International Psycho-Oncology Society Research Committee. Patient-reported depression measures in cancer: A meta-review. Lancet Psychiatry 2015, 2, 635-647. [CrossRef]

10. Rehm, J.; Shield, K.D. Global Burden of Disease and the Impact of Mental and Addictive Disorders. Curr. Psychiatry Rep. 2019, 21, 10. [CrossRef] 
11. Li, Z.; Wang, W.; Xin, X.; Song, X.; Zhang, D. Association of total zinc, iron, copper and selenium intakes with depression in the US adults. J. Affect. Disord. 2018, 228, 68-74. [CrossRef] [PubMed]

12. Nakamura, M.; Miura, A.; Nagahata, T.; Shibata, Y.; Okada, E.; Ojima, T. Low Zinc, Copper, and Manganese Intake is Associated with Depression and Anxiety Symptoms in the Japanese Working Population: Findings from the Eating Habit and Well-Being Study. Nutrients 2019, 11, 847. [CrossRef]

13. Sánchez-Villegas, A.; Álvarez-Pérez, J.; Toledo, E.; Salas-Salvadó, J.; Ortega-Azorín, C.; Zomeño, M.D.; Vioque, J.; Martínez, J.A.; Romaguera, D.; Pérez-López, J.; et al. Seafood Consumption, Omega-3 Fatty Acids Intake, and Life-Time Prevalence of Depression in the PREDIMED-Plus Trial. Nutrients 2018, 10, 2000. [CrossRef] [PubMed]

14. Anglin, R.E.; Samaan, Z.; Walter, S.D.; McDonald, S.D. Vitamin D deficiency and depression in adults: Systematic review and meta-analysis. Br. J. Psychiatry 2013, 202, 100-107. [CrossRef] [PubMed]

15. Perez-Cornago, A.; Sanchez-Villegas, A.; Bes-Rastrollo, M.; Gea, A.; Molero, P.; Lahortiga-Ramos, F.; Martinez-Gonzalez, M.Á. Relationship between adherence to Dietary Approaches to Stop Hypertension (DASH) diet indices and incidence of depression during up to 8 years of follow-up. Public Health Nutr. 2017, 20, 2383-2392. [CrossRef] [PubMed]

16. Cherian, L.; Wang, Y.; Holland, T.; Agarwal, P.; Aggarwal, N.; Morris, M.C. DASH and Mediterranean-Dash Intervention for Neurodegenerative Delay (MIND) Diets are Associated with Fewer Depressive Symptoms Over Time. J. Gerontol. A Biol. Sci. Med. Sci. 2020. [CrossRef]

17. Fresán, U.; Bes-Rastrollo, M.; Segovia-Siapco, G.; Sanchez-Villegas, A.; Lahortiga, F.; de la Rosa, P.A.; Martínez-Gonzalez, M.A. Does the MIND diet decrease depression risk? A comparison with Mediterranean diet in the SUN cohort. Eur. J. Nutr. 2019, 58, 1271-1282. [CrossRef]

18. National Health and Nutrition Examination Survey. Available online: https://www.cdc.gov/nchs/nhanes/about_nhanes.htm (accessed on 15 June 2020).

19. Nutrition and Your Health: 2015-2020 Dietary Guidelines for Americans, 8th ed.; US Government Printing Office: Washington, DC, USA, 2015. Available online: https:/ / health.gov/our-work/food-nutrition/previous-dietary-guidelines/2015 (accessed on 20 May 2020).

20. Krebs-Smith, S.M.; Pannucci, T.E.; Subar, A.F.; Kirkpatrick, S.I.; Lerman, J.L.; Tooze, J.A.; Wilson, M.M.; Reedy, J.; Reedy, J. Update of the Healthy Eating Index: HEI-2015. J. Am. Acad. Nutr. Diet. 2018, 118, 1591-1602. [CrossRef]

21. Cruz, N.; Shabaneh, O.; Appiah, D. The Association of Ideal Cardiovascular Health and Ocular Diseases among U.S Adults. Am. J. Med. 2020. [CrossRef]

22. Kroenke, K.; Spitzer, R.L.; Williams, J.B. The PHQ-9: Validity of a brief depression severity measure. J. Gen. Intern. Med. 2001, 16, 606-613. [CrossRef]

23. Tsai, J.; Homa, D.M.; Gentzke, A.S.; Mahoney, M.; Sharapova, S.R.; Sosnoff, C.S.; Caron, K.T.; Wang, L.; Melstrom, P.C.; Trivers, K.F. Exposure to Secondhand Smoke Among Nonsmokers-United States, 1988-2014. MMWR Morb. Mortal. Wkly. Rep. 2018, 67, 1342-1346. [CrossRef]

24. Scholes, S.; Bann, D. Education-related disparities in reported physical activity during leisure-time, active transportation, and work among US adults: Repeated cross-sectional analysis from the National Health and Nutrition Examination Surveys, 2007 to 2016. BMC Public Health 2018, 18, 926. [CrossRef]

25. Montgomery, J.; Lu, J.; Ratliff, S.; Mezuk, B. Food Insecurity and Depression among Adults with Diabetes: Results from the National Health and Nutrition Examination Survey (NHANES). Diabetes Educ. 2017, 43, 260-271. [CrossRef] [PubMed]

26. Dreimüller, N.; Lieb, K.; Tadić, A.; Engelmann, J.; Wollschläger, D.; Wagner, S. Body mass index (BMI) in major depressive disorder and its effects on depressive symptomatology and antidepressant response. J. Affect. Disord. 2019, 256, 524-531. [CrossRef] [PubMed]

27. ALHarthi, S.S.Y.; Natto, Z.S.; Midle, J.B.; Gyurko, R.; O’Neill, R.; Steffensen, B. Association between time since quitting smoking and periodontitis in former smokers in the National Health and Nutrition Examination Surveys (NHANES) 2009 to 2012. J. Periodontol. 2019, 90, 16-25. [CrossRef] [PubMed]

28. Gay Isabel, C.; Tran Duong, T.; Paquette David, W. Alcohol intake and periodontitis in adults aged $\geq 30$ years: NHANES 2009-2012. J. Periodontol. 2018, 89, 625-634.

29. Caspard, H.; Jabbour, S.; Hammar, N.; Fenici, P.; Sheehan, J.J.; Kosiborod, M. Recent trends in the prevalence of type 2 diabetes and the association with abdominal obesity lead to growing health disparities in the USA: An analysis of the NHANES surveys from 1999 to 2014. Diabetes Obes. Metab. 2018, 20, 667-671. [CrossRef] [PubMed]

30. Rao, J.N.K.; Scott, A.J. On Simple Adjustments to Chi-Square Tests with Sample Survey Data. Ann. Stat. 1987, 15, 385-397. [CrossRef]

31. Salk, R.H.; Hyde, J.S.; Abramson, L.Y. Gender differences in depression in representative national samples: Meta-analyses of diagnoses and symptoms. Psychol. Bull. 2017, 143, 783-822. [CrossRef]

32. Culbertson, F.M. Depression and gender. An international review. Am. Psychol. 1997, 52, 25-31. [CrossRef]

33. Fletcher, J.M. Adolescent depression and educational attainment: Results using sibling fixed effects. Health Econ. 2010, 19 , 855-871. [CrossRef]

34. Korhonen, K.; Remes, H.; Martikainen, P. Education as a social pathway from parental socioeconomic position to depression in late adolescence and early adulthood: A Finnish population-based register study. Soc. Psychiatry Psychiatr. Epidemiol. 2017, 52, 105-116. [CrossRef] 
35. Freeman, A.; Tyrovolas, S.; Koyanagi, A.; Chatterji, S.; Leonardi, M.; Ayuso-Mateos, J.L.; Tobiasz-Adamczyk, B.; Koskinen, S.; Rummel-Kluge, C.; Haro, J.M. The role of socio-economic status in depression: Results from the COURAGE (aging survey in Europe). BMC Public Health 2016, 16, 1098. [CrossRef] [PubMed]

36. Çakıcı, M.; Gökçe, Ö.; Babayiğit, A.; Çakıc1, E.; Eş, A. Depression: Point-prevalence and risk factors in a North Cyprus household adult cross-sectional study. BMC Psychiatry 2017, 17, 387. [CrossRef] [PubMed]

37. Gero, K.; Kondo, K.; Kondo, N.; Shirai, K.; Kawachi, I. Associations of relative deprivation and income rank with depressive symptoms among older adults in Japan. Soc. Sci. Med. 2017, 189, 138-144. [CrossRef] [PubMed]

38. Fukuda, Y.; Hiyoshi, A. Influences of income and employment on psychological distress and depression treatment in Japanese adults. Environ. Health Prev. Med. 2012, 17, 10-17. [CrossRef]

39. Tomita, A.; Manuel, J.I. Evidence on the Association Between Cigarette Smoking and Incident Depression from the South African National Income Dynamics Study 2008-2015: Mental Health Implications for a Resource-Limited Setting. Nicotine Tob. Res. 2020, 22, 118-123. [CrossRef]

40. Luger, T.M.; Suls, J.; Vander Weg, M.W. How robust is the association between smoking and depression in adults? A meta-analysis using linear mixed-effects models. Addict. Behav. 2014, 39, 1418-1429. [CrossRef]

41. Tjora, T.; Hetland, J.; Aarø, L.E.; Wold, B.; Wiium, N.; Øverland, S. The association between smoking and depression from adolescence to adulthood. Addiction 2014, 109, 1022-1030. [CrossRef]

42. Shafer, K.; Pace, G.T. Gender differences in depression across parental roles. Soc. Work 2015, 60, 115-125. [CrossRef]

43. Ul-Haq, Z.; Mackay, D.F.; Fenwick, E.; Pell, J.P. Association between body mass index and mental health among Scottish adult population: A cross-sectional study of 37,272 participants. Psychol. Med. 2014, 44, 2231-2240. [CrossRef]

44. Bagnardi, V.; Rota, M.; Botteri, E.; Tramacere, I.; Islami, F.; Fedirko, V.; Scotti, L.; Jenab, M.; Turati, F.; Pasquali, E.; et al. Light alcohol drinking and cancer: A meta-analysis. Ann. Oncol. 2013, 24, 301-308. [CrossRef]

45. Xu, W.; Wang, H.; Wan, Y.; Tan, C.; Li, J.; Tan, L.; Yu, J.T. Alcohol consumption and dementia risk: A dose-response meta-analysis of prospective studies. Eur. J. Epidemiol. 2017, 32, 31-42. [CrossRef] [PubMed]

46. Larsson, S.C.; Wallin, A.; Wolk, A. Alcohol consumption and risk of heart failure: Meta-analysis of 13 prospective studies. Clin. Nutr. 2018, 37, 1247-1251. [CrossRef] [PubMed]

47. Larsson, S.C.; Wallin, A.; Wolk, A.; Markus, H.S. Differing association of alcohol consumption with different stroke types: A systematic review and meta-analysis. BMC Med. 2016, 14, 178. [CrossRef] [PubMed]

48. Knott, C.; Bell, S.; Britton, A. Alcohol Consumption and the Risk of Type 2 Diabetes: A Systematic Review and Dose-Response Meta-analysis of More Than 1.9 Million Individuals from 38 Observational Studies. Diabetes Care 2015, 38, 1804-1812. [CrossRef] [PubMed]

49. Xi, B.; Veeranki, S.P.; Zhao, M.; Ma, C.; Yan, Y.; Mi, J. Relationship of Alcohol Consumption to All-Cause, Cardiovascular, and Cancer-Related Mortality in U.S. Adults. J. Am. Coll. Cardiol. 2017, 70, 913-922, Erratum in: J. Am. Coll. Cardiol. 2017, 70, 1542. [CrossRef] [PubMed]

50. Alati, R.; Lawlor, D.A.; Najman, J.M.; Williams, G.M.; Bor, W.; O'Callaghan, M. Is there really a 'J-shaped' curve in the association between alcohol consumption and symptoms of depression and anxiety? Findings from the Mater-University Study of Pregnancy and its outcomes. Addiction 2005, 100, 643-651. [CrossRef]

51. Korczak, D.J.; Madigan, S.; Colasanto, M. Children's Physical Activity and Depression: A Meta-analysis. Pediatrics 2017, 139, e20162266. [CrossRef]

52. Kandola, A.; Ashdown-Franks, G.; Hendrikse, J.; Sabiston, C.M.; Stubbs, B. Physical activity and depression: Towards understanding the antidepressant mechanisms of physical activity. Neurosci. Biobehav. Rev. 2019, 107, 525-539. [CrossRef]

53. Choi, K.W.; Chen, C.Y.; Stein, M.B.; Klimentidis, Y.C.; Wang, M.J.; Koenen, K.C.; Smoller, J.W.; Major Depressive Disorder Working Group of the Psychiatric Genomics Consortium. Assessment of Bidirectional Relationships between Physical Activity and Depression among Adults: A 2-Sample Mendelian Randomization Study. JAMA Psychiatry 2019, 76, 399-408. [CrossRef]

54. Kvam, S.; Kleppe, C.L.; Nordhus, I.H.; Hovland, A. Exercise as a treatment for depression: A meta-analysis. J. Affect. Disord. 2016, 202, 67-86. [CrossRef]

55. Ley, S.H.; Hamdy, O.; Mohan, V.; Hu, F.B. Prevention and management of type 2 diabetes: Dietary components and nutritional strategies. Lancet 2014, 383, 1999-2007. [CrossRef]

56. Ley, S.H.; Pan, A.; Li, Y.; Manson, J.E.; Willett, W.C.; Sun, Q.; Hu, F.B. Changes in Overall Diet Quality and Subsequent Type 2 Diabetes Risk: Three U.S. Prospective Cohorts. Diabetes Care 2016, 39, 2011-2018. [CrossRef] [PubMed]

57. Anderson, R.J.; Freedland, K.E.; Clouse, R.E.; Lustman, P.J. The prevalence of comorbid depression in adults with diabetes: A meta-analysis. Diabetes Care 2001, 24, 1069-1078. [CrossRef] [PubMed] 